Check for updates

Cite this: Nanoscale Adv., 2019, 1, 1193

\title{
A green method for the production of an efficient bioimaging nanotool
}

\author{
Ermelinda Bloise, (D) $\uparrow^{\star a}$ Maria Pia Di Bello, $\uparrow^{a}$ Giuseppe Mele ${ }^{a}$ and Loris Rizzello*b
}

The possibility of exploring basic biological phenomena requires the development of new and efficient bioimaging tools. These should ideally combine the feasibility of production (potentially through the use of green chemistry) together with high targeting efficiency, low cytotoxicity, and optimal contrast characteristics. In this work, we developed nanovesicles based on cardanol, a natural and renewable byproduct of the cashew industry, and a fluorescent reporter was encapsulated in them through an environment-friendly synthesis method. In vitro investigations demonstrated that the cardanol nanovesicles are efficiently taken-up by both professional and non-professional phagocytic cells, which have been modeled in our approach by macrophages and HeLa cells, respectively. Co-localization studies show high affinity of the nanovesicles towards the cell plasma membrane. Moreover, metabolic assays confirmed that these nanostructures are biocompatible in a specific concentration range, and do not promote inflammation response in human macrophages. Stability studies carried out at different temperatures showed that the nanovesicles are stable at both $37^{\circ} \mathrm{C}$ and $20^{\circ} \mathrm{C}$, while the formation of aggregates occurs when the nanodispersion is incubated at $4{ }^{\circ} \mathrm{C}$. The results demonstrate the high potential of fluorescent cardanol nanovesicles as a green bioimaging tool, especially for investigating cell membrane dynamics.

Received 9th November 2018

Accepted 21st December 2018

DOI: $10.1039 / c 8 n a 00336 j$

rsc.li/nanoscale-advances polymers from renewable resources, have thus been broadly exploited as preferential starting materials for developing delivery platforms. ${ }^{9-11}$ Dextran nanovesicles responsive to acidic $\mathrm{pH}$ and/ or esterase, and chitosan nanoparticles for cancer targeting are only some examples. ${ }^{12-14} \mathrm{~A}$ recent trend is also the development of drug-loaded bioactive nanocarriers made from natural oils (such as grapeseed oil, fish oil and laurel leaf oil) and surfactant mixtures, as these are able to reduce harmful free radicals and eradicate cancer cells. ${ }^{15}$

Among the plethora of nature-inspired products that can be exploited as a backbone for delivery systems, cardanol (CA) has received great attention. This is due to the CA structural features that make it suitable for feasible chemical modifications. CA is a renewable raw material obtained as a byproduct of the cashew industry by distillation of the cashew nut shell liquid (CNSL). Several data proved that CNSL and its derivatives possess interesting in vitro and in vivo biological functions, including antioxidant, antimicrobial, anti-cancer and larvicidal activities. ${ }^{16-21} \mathrm{CA}$ is able to form a stable nanovesicle dispersion upon combination with cholesterol, ${ }^{22,23}$ showing good antioxidant and cytotoxic properties, ${ }^{24}$ and a potential stabilization capability towards the encapsulated molecules. ${ }^{25} \mathrm{~A}$ new challenge nowadays is, hence, the possibility of creating a biocompatible drug delivery system starting from waste materials, which can also be potentially used as a bioimaging tool..$^{26-30}$

In this framework, we aimed here to produce CA-based nanovesicles, and to use them as a platform to develop
${ }^{a}$ University of Salento, Department of Engineering for Innovation, Via Arnesano, 73100, Lecce, Italy. E-mail: ermelinda.bloise@unisalento.it

${ }^{b}$ Institute for Bioengineering of Catalonia (IBEC), C/Baldiri Reixac 15-21, 08028 Barcelona, Spain. E-mail: lrizzello@ibecbarcelona.eu; Tel: +34934039956

$\dagger$ These authors equally contributed to this work. 
a green system for imaging biological specimens. We demonstrated that CA-nanovesicles (CANVs) can efficiently encapsulate rhodamine $\mathrm{B}(\mathrm{RhB})$ through an organic solvent-free procedure, and be delivered to human macrophages (MФ) and HeLa cells, which show an efficient active uptake process. Moreover, we confirmed that these CANVs are biocompatible up to specific concentrations, and do not induce any inflammation process in MФ. Stability studies of the CANVs were performed at three different temperatures $\left(37,20\right.$ and $\left.4{ }^{\circ} \mathrm{C}\right)$ by monitoring the nanosystem components (CA and $\mathrm{CH}$ ) over time through HPLCDAD-MS analyses, coupled with Dynamic Light Scattering (DLS)-based evaluation of size, and $\zeta$-potential for surface charge characterization.

\section{Experimental}

\section{A. Materials}

CA was kindly furnished by Oltremare S.r.l. Rhodamine B (RhB) was purchased from Alfa Aesar (Alfa Aesar GmbH\&Co, KG, Germany). Cholesterol $(\mathrm{CH})$, potassium chloride $(\mathrm{KCl})$, boric acid $\left(\mathrm{H}_{3} \mathrm{BO}_{4}\right)$, sodium hydroxide $(\mathrm{NaOH})$, acetonitrile $\left(\mathrm{CH}_{3} \mathrm{CN}\right)$, methanol (MeOH) for HPLC, isopropyl alcohol (IPA), and acetic acid were purchased from Sigma-Aldrich®. Ultrapure (UP) water was delivered by a Zeneer UP 900 Human Corporation system. Borate buffer solution, $\mathrm{pH}$ 9.0, is an UP water solution of $\mathrm{H}_{3} \mathrm{BO}_{4}$ $30 \mathrm{mM}, \mathrm{KCl} 70 \mathrm{mM}$, and $\mathrm{NaOH} 18 \mathrm{mM}$. Sonication was carried out using a Sonorex RK $102 \mathrm{H}$ ultrasonic water bath from Bandelin Electronic. Centrifugation was carried out with a PK121 multispeed centrifuge from Thermo Electron Corporation. Cervical human cancer cells (HeLa) and human THP-1 leukemia monocyte cells were purchased from ATCC®. Dulbecco's Modified Eagle Medium (DMEM), fetal calf serum, L-glutamine, streptomycin, penicillin, trypsin-EDTA solution, RPMI-1640 medium, HEPES buffer, thiazolyl blue tetrazolium blue (MTT), phosphate-buffered saline (PBS), 4',6-diamidino-2-phenylindole (DAPI), bacterial lipopolysaccharide (LPS), and phorbol 12myristate 13-acetate (PMA) were purchased from SigmaAldrich®. CellMask was purchased from Life Technologies, and THP-1 blue NF- $\mathrm{B}$ reporter cells were purchased from InvivoGen.

\section{B. Preparation of cardanol-based nanovesicles}

RhB dye was mixed with $\mathrm{CA}, \mathrm{CH}$ (molar ratio $0.04: 1: 0.6$, respectively), and glass beads (10 g, diameter of $4 \mathrm{~mm}$ ) by mechanical stirring at $200 \mathrm{rpm}$ at $90{ }^{\circ} \mathrm{C}$ for $1 \mathrm{~h}$ to form a lipid film on the flask's wall. The resulting film was hydrated with $40 \mathrm{~mL}$ of borate buffer at $\mathrm{pH} 9.0$, preheated at $50{ }^{\circ} \mathrm{C}$, under mechanical stirring $(800 \mathrm{rpm})$, and finally heated at $90{ }^{\circ} \mathrm{C}$ for $1 \mathrm{~h}$. Then, the obtained vesicular nanodispersion was sonicated for $15 \mathrm{~min}$ at $60{ }^{\circ} \mathrm{C}$, and then centrifuged (7000 rpm for $15 \mathrm{~min}$ ) to collect the supernatant as the sample. Purification of the nanodispersion from non-entrapped $\mathrm{RhB}$ was performed by exhaustive dialysis. The sample was transferred into a dialysis tubing cellulose membrane $(12 \mathrm{kDa})$ and then sealed at both ends with clips and dialyzed against borate buffer solution, $\mathrm{pH}$ 9.0, for some days. Fresh buffer solution was replaced every day, and the free $\mathrm{RhB}$ was monitored at $554 \mathrm{~nm}$ through UV-vis measurements using a Jasco V-660 spectrophotometer until disappearance of the signal. A sample without dye was prepared with the same procedure as that for the blank reference.

\section{Dynamic light scattering analysis}

Measurements of dynamic light scattering (DLS) and electrophoretic light scattering were both carried out on a Malvern Zetasizer Nano ZS90 on samples diluted with UP water to establish the size and $\zeta$-potential of nanovesicles. The hydrodynamic diameter $(d)$ of the vesicle nanodispersion was determined at $25{ }^{\circ} \mathrm{C}$ measuring the autocorrelation function at a $90^{\circ}$ scattering angle. Each $d$ value is the average of three separate measurements. The $\zeta$-potential values of nanovesicles were determined at $25{ }^{\circ} \mathrm{C}$ from an average of 3 measurements. The voltage ramps were performed according to the DLS manufacturer instructions.

\section{HPLC-DAD-MS analysis}

Separation and quantification of nanocarrier components (CA and $\mathrm{CH}$ ) were performed on an Agilent Technologies (Waldbronn, Germany) modular model 1200 system, consisting of a vacuum degasser, a binary pump, an autosampler, a fixedtemperature column compartment, and a diode array detector (DAD). Natural CA extract is a mixture of compounds and was used as such as a standard to develop a calibration curve in the range 10-1000 $\mathrm{mg} \mathrm{L}^{-1}$. For CA quantification nanovesicles were lysed by adding $5 \mathrm{~mL}$ of $\mathrm{MeOH}$ to $1 \mathrm{~mL}$ of samples, then dried, resuspended in $1 \mathrm{~mL}$ of $\mathrm{CH}_{3} \mathrm{CN}$, and passed through a $0.22 \mu \mathrm{m}$ nylon filter before injection. The chromatograms were recorded using Agilent Mass Hunter software (rev. B.06.00). Chromatography separation was carried out on a $150 \times 4.6 \mathrm{~mm}$ i.d., $5 \mu \mathrm{m}$ Gemini C18 column set at $25{ }^{\circ} \mathrm{C}$. The mobile phase was composed of water/acetic acid $0.1 \% \mathrm{v} / \mathrm{v}$ (solvent $\mathrm{A}$ ) and $\mathrm{CH}_{3} \mathrm{CN}$ (solvent B). The chromatograms were acquired at a wavelength of $280 \mathrm{~nm}$ working at a flow rate of $0.8 \mathrm{~mL} \mathrm{~min}{ }^{-1}$, with the following gradient: $0 \mathrm{~min}, 50 \% \mathrm{~B} ; 20 \mathrm{~min}, 100 \% \mathrm{~B}$; and $32 \mathrm{~min}$, $100 \% \mathrm{~B}$. Three injections were performed for each sample, and the results are the average of those values.

Qualitative analyses of CA were carried out after chromatographic separation using the same system equipped with a 6540 quadrupole time-of-flight (QTOF) mass analyzer with an electrospray ionization (ESI) source. The HPLC-ESI-MS analyses of the CA components were performed both in negative-ion mode and in positive-ion mode. ${ }^{25}$ Quantification of $\mathrm{CH}$ was performed using a curve in the range $10-1000 \mathrm{mg} \mathrm{L}^{-1}$. Nanovesicles were lysed by adding $5 \mathrm{~mL}$ of $\mathrm{MeOH}$ to $1 \mathrm{~mL}$ of samples, then dried, resuspended in $1 \mathrm{~mL}$ of mixed solvent $\mathrm{CH}_{3} \mathrm{CN} / \mathrm{MeOH} / \mathrm{IPA}$ ( $7: 3: 1, \mathrm{v} / \mathrm{v} / \mathrm{v})$ and passed through a $0.22 \mu \mathrm{m}$ nylon filter before injection. The chromatograms were recorded using the Agilent Mass Hunter software mentioned above. Chromatography separation was carried out on a $150 \times 4.6 \mathrm{~mm}$ i.d., $5 \mu \mathrm{m}$ Gemini C18 column set at $25^{\circ} \mathrm{C}$. The isocratic mobile phase was composed of $\mathrm{CH}_{3} \mathrm{CN} / \mathrm{MeOH} / \mathrm{IPA}(7: 3: 1, \mathrm{v} / \mathrm{v} / \mathrm{v})$. The chromatograms were acquired at a wavelength of $202 \mathrm{~nm}$ working at 
a flow rate of $1 \mathrm{~mL} \mathrm{~min}^{-1} \cdot{ }^{31}$ Three injections were performed for each sample, and the results are the average of those values.

\section{E. Nanovesicle stability studies}

Stability studies were carried out on stored CANV samples at three different temperatures $\left(37^{\circ} \mathrm{C}, 20^{\circ} \mathrm{C}\right.$ and $\left.4{ }^{\circ} \mathrm{C}\right)$ for $3,4,7$ and 10 days. Stability profiles were obtained by monitoring their $d$ and $\zeta$-potential by DLS analysis and the CA and $\mathrm{CH}$ concentrations by HPLC-DAD. The equation used to calculate the percentage of CA and $\mathrm{CH}$ in nanovesicle samples [analyte (\%)] is as follows:

$$
\text { analyte } \%=\frac{C_{\text {days }}}{C_{0}} \times 100
$$

where $C_{\text {days }}$ is the analyte concentration determined at different days, whereas $C_{0}$ is the analyte concentration determined on the fresh sample.

\section{F. Cell uptake and metabolic assay}

HeLa cells were cultured and maintained using DMEM containing $10 \%(\mathrm{v} / \mathrm{v})$ fetal calf serum, $2 \mathrm{mM}$ L-glutamine, $100 \mathrm{mg}$ $\mathrm{mL}^{-1}$ streptomycin and $100 \mathrm{IU} \mathrm{mL}^{-1}$ penicillin. Cells were cultured at $37{ }^{\circ} \mathrm{C} / 95 \%$ air $/ 5 \% \mathrm{CO}_{2}$. Cells were periodically subcultured using trypsin-EDTA solution $0.25 \%$ for the detachment process and centrifuged at $300 \mathrm{~g}$ for $5 \mathrm{~min}$ for the pellet collection. THP-1 cells were cultured and maintained in RPMI1640 medium, supplemented with $10 \mathrm{mM}$ HEPES buffer, 10\% $(\mathrm{v} / \mathrm{v})$ fetal calf serum, $2 \mathrm{mM}$ L-glutamine, $100 \mathrm{mg} \mathrm{mL}^{-1}$ streptomycin and $100 \mathrm{IU} \mathrm{mL}^{-1}$ penicillin. THP-1 monocytes were differentiated to macrophages through incubation with $5 \mathrm{ng}$ $\mathrm{mL}^{-1}$ PMA for 48 hours. ${ }^{32}$ We chose this PMA concentration as it does not modify the regulation of stress- and inflammationrelated genes. ${ }^{33}$ For the metabolic assay, the MTT method was used. Briefly, cells were seeded at a concentration of $5 \times 10^{3}$ cells per well in a 96 well plate overnight. Increasing concentrations of CANVs were then added in the growth media, namely $5,10,30,50$, and $70 \mu \mathrm{g} \mathrm{mL}{ }^{-1}$, for 24 and 48 hours. The growth medium was then removed, and the tetrazolium blue salt was added for 2 hours. An acidified solution of isopropanol was then added to dissolve the water-insoluble MTT formazan. The solubilized blue crystals were measured colorimetrically at $570 \mathrm{~nm}$ (plate reader ELx800, BioTek). For uptake imaging analyses, HeLa and THP-1 cells were seeded on glass-bottom Petri dishes (Ibidi) at a concentration of $5 \times 10^{3}$ cells per well, and incubated with RhB-labeled CANVs $\left(0.1 \mathrm{mg} \mathrm{mL}^{-1}\right)$ for 24 and 48 hours, followed by 3 steps of PBS washing. Cells were then stained with DAPI for nuclear staining, and far-red CellMask for cell membrane staining and imaged with a confocal microscope (Leica SP8). For the uptake quantification, 10 different regions of the Petri dishes were captured, and the fluorescent signal was normalized to the nuclear intensity signal (using ImageJ).

\section{G. Quantification of $\mathbf{M}(\boldsymbol{\Phi})$ inflammation levels}

For the quantification of M $\Phi$ inflammation levels, THP-1 blue $\mathrm{NF}-\kappa \mathrm{B}$ reporter cells were used. These cells are stably transfected and express a secreted embryonic alkaline phosphatase (SEAP) reporter gene driven by an IFN-beta minimal promoter fused to five copies of the NF- $\kappa \mathrm{B}$ transcription factor, which promotes cytokine production. The translocation of NF$\kappa \mathrm{B}$ from the cytosol to the nucleus induces the release of the SEAP phosphatase, whose activity can be monitored colorimetrically. THP-1 blue NF- $\kappa \mathrm{B}$ reporter cells were differentiated into $\mathrm{M} \Phi$ as previously described, and then incubated with 200 $\mathrm{ng} \mathrm{mL}^{-1}$ bacterial LPS as a positive control, and with $30 \mu \mathrm{g}$ $\mathrm{mL}^{-1}$ CANVs for 24 and 48 hours. $20 \mu \mathrm{L}$ of media were then removed and incubated with the incubation media, according to the manufacturer's instructions. The quantification of media color change was performed with a spectrophotometer (plate reader ELx800, BioTek) by reading at $570 \mathrm{~nm}$.

\section{Results and discussion}

The CA used as the main constituent of the green nanocarrier by a mixture of differently (un)saturated compounds (Fig. 1). Hence, HPLC-DAD-MS analyses were preliminarily used to determine the CA composition. ${ }^{25}$ Four main components were found, corresponding to three unsaturated components, 3$\left[8(Z), 11(Z), 14\right.$-pentadecatrienyl]phenol $\quad\left(\mathrm{C}_{15: 3}\right), \quad 3-[8(Z), 11(Z)$ pentadecadienyl]phenol $\left(\mathrm{C}_{15: 2}\right)$, and 3-[8(Z)-pentadecadecenyl] phenol $\left(\mathrm{C}_{15: 1}\right)$, and the saturated component 3 - $n$-pentadecylphenol $\left(\mathrm{C}_{15: 0}\right)$. For CA quantification, the most abundant monounsaturated $\mathrm{C}_{15: 1}$ component was considered. The stability of the nanovesicles was investigated by monitoring the change of $\mathrm{CA}$ and $\mathrm{CH}$ concentrations, and modification in the size distribution and $\zeta$-potential values over time. This was done while incubating the CANVs in glass tubes at three different temperatures $\left(37^{\circ} \mathrm{C}, 20^{\circ} \mathrm{C}\right.$ and $\left.4{ }^{\circ} \mathrm{C}\right)$. The size distribution $(d)$ and $\zeta$-potential values for all samples are displayed in Fig. 2A. Nanovesicles are stable at both $37{ }^{\circ} \mathrm{C}$ and $20{ }^{\circ} \mathrm{C}$, as their size distribution is not affected. However, incubation at $4{ }^{\circ} \mathrm{C}$ led to a significant increase of the mean diameter, thus indicating the formation of aggregates. We have further characterized the change in the physicochemical parameters of CANVs as a function of temperature, and quantified the variations in $\mathrm{CA}$ and $\mathrm{CH}$ concentration over time. These data further indicate that incubation at $4{ }^{\circ} \mathrm{C}$ decreases the stability of CANVs as confirmed by the decrease of CA and $\mathrm{CH}$ concentration (Fig. 2B). Transmission electron microscopy (TEM)-based analyses confirmed

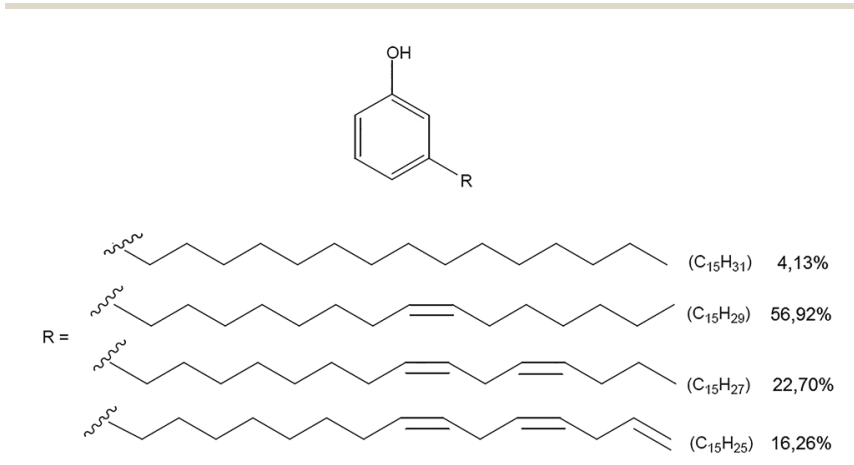

Fig. 1 Composition of the CA mixture. 

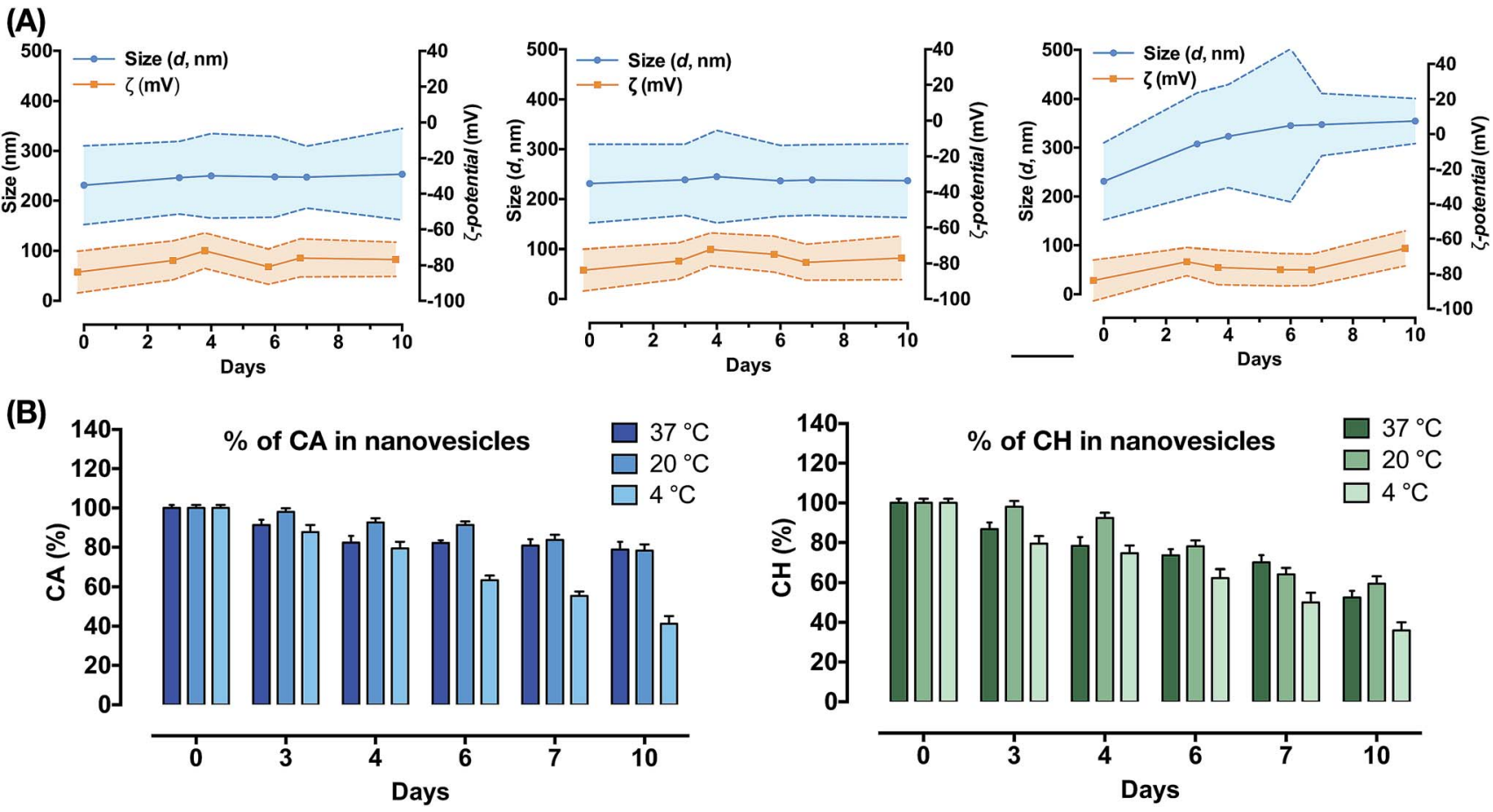

Fig. 2 Physicochemical characterization of CA nanovesicles. (A) Stability studies based on DLS for size distribution (blue graph, quantified on the left $y$ axis) and $\zeta$-potential for surface charge analysis (orange graph, quantified on the right $y$ axis). (B) Variations in $\mathrm{CA}$ and $\mathrm{CH}$ concentration over time, as a function of environmental temperature.

that the morphology of the green nanocarriers is characterized by a very regular spherical structure, as we have already reported in our previous studies. ${ }^{23,24}$ After analyzing the physicochemical parameters of the "green" CANVs, and their stability as a function of the environmental temperature, we addressed their interactions with cells. As model systems, we used human cervical cancer (HeLa) cells, and leukemic monocytes (THP-1), differentiated to a macrophage (M $\Phi$ ) phenotype (see the Experimental section). We encapsulated RhB under solvent-free conditions within the CANVs. RhB-encapsulated CANVs were incubated with cells, and the kinetics of uptake were studied by confocal microscopy (Fig. 3). We have observed an increase in the relative fluorescence intensity in HeLa cells (i.e., the fluorescence of RhB-encapsulated CANVs normalized by the number of cells) from $c a$. 0.7 to 1 , corresponding to 24 and 48 hours of incubation, respectively (Fig. 3A). Moreover, the quantification of the Pearson coefficient, which is a measure of the spatial overlap between two different signals, confirms that there is almost $85 \%$ signal co-localization between the nanovesicles and the plasma membrane. The value rises up to $c a$. $90 \%$ after 48 hours of incubation. This suggests that the nanovesicles tend to interact with the plasma membrane, and while some of these will undergo an internalization process through endocytosis, a significant number of nanovesicles remain at the membrane level. We have also observed similar uptake profiles for $\mathrm{M} \Phi$, as the normalized fluorescence intensity of the RhB-encapsulated CANVs increased from $c a$. 0.6 to 1 , which corresponds to 24 and 48 hours of incubation with cells (Fig. 3B). In this case, however, the Pearson coefficient had lower values with respect to HeLa cells. In particular, it was about $62 \%$ after 24 hours and $c a .70 \%$ after 48 hours of incubation with nanovesicles (Fig. 3B). This would suggest that the nanovesicles interact less with the plasma membrane of $\mathrm{M} \Phi$ compared to the stronger interaction with the membrane of HeLa cells. This can be ascribed to the different uptake processes of the two cells. HeLa cells engulf materials only by endocytic processes while $M \Phi$ combine endocytosis with phagocytosis (typical of professional phagocytes). This means, in turn, that the dwelling time of nanoparticles at the plasma membrane level in $\mathrm{M} \Phi$ might be lower compared to that in HeLa because M $\Phi$ are much more efficient in performing nanovesicle engulfment. After analyzing the uptake profile of the nanovesicles, we addressed their effects on both cells. Hence, we carried out metabolic assays to test the potential toxicity of the CANVs as a function of concentration and incubation time. CANVs did not induce any decrease in cell viability at 5,10 , and $30 \mu \mathrm{g} \mathrm{mL}^{-1}$ after 24 hours of incubation with HeLa cells (Fig. 4A, left), while the viability dropped to $c a$. $40 \%$ upon incubation with $50 \mu \mathrm{g} \mathrm{mL} \mathrm{m}^{-1}$ (hence close to their $\mathrm{IC}_{50}$ ). The nanovesicles displayed significant toxicity at $70 \mu \mathrm{g} \mathrm{mL} L^{-1}$, where no viable HeLa cells were detected (Fig. 4A, left). Similarly, CANVs did not induce toxicity after 48 hours at 5 and $10 \mu \mathrm{g}$ $\mathrm{mL}^{-1}$, while at 30 and $50 \mu \mathrm{g} \mathrm{mL} \mathrm{m}^{-1}$ they were slightly more toxic with respect to the 24 hour case. Also in this case, $70 \mu \mathrm{g} \mathrm{mL}$ was lethal to HeLa. With respect to $M \Phi$, significant toxicity was detected starting from $50 \mu \mathrm{g} \mathrm{mL} \mathrm{m}^{-1}$ CANVs after 24 and 48 hours of incubation (Fig. 4A, right). As for HeLa, $70 \mu \mathrm{g} \mathrm{mL} \mathrm{m}^{-1}$ CANVs resulted also lethal for $\mathrm{M} \Phi$. We then went deeper into the 

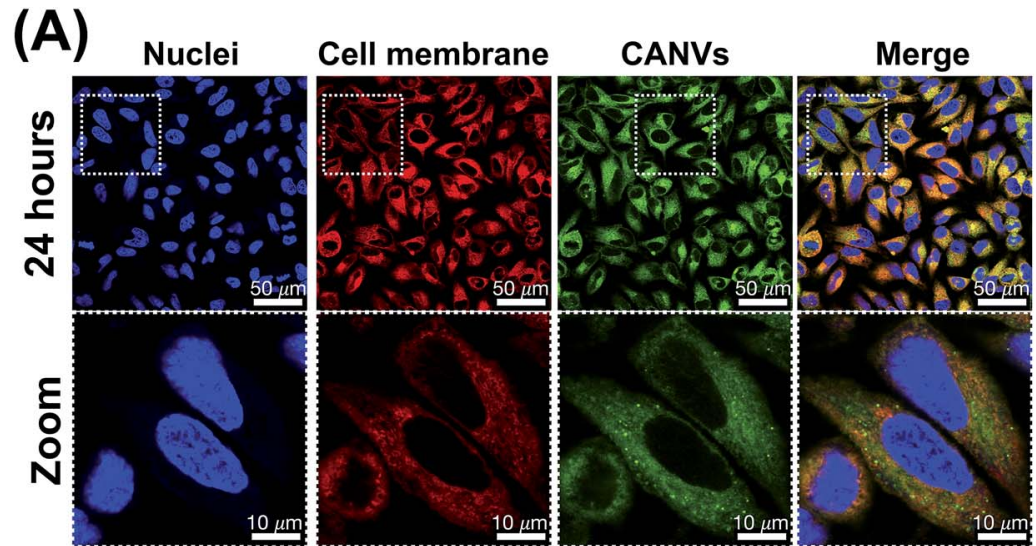

\section{Uptake quantification}
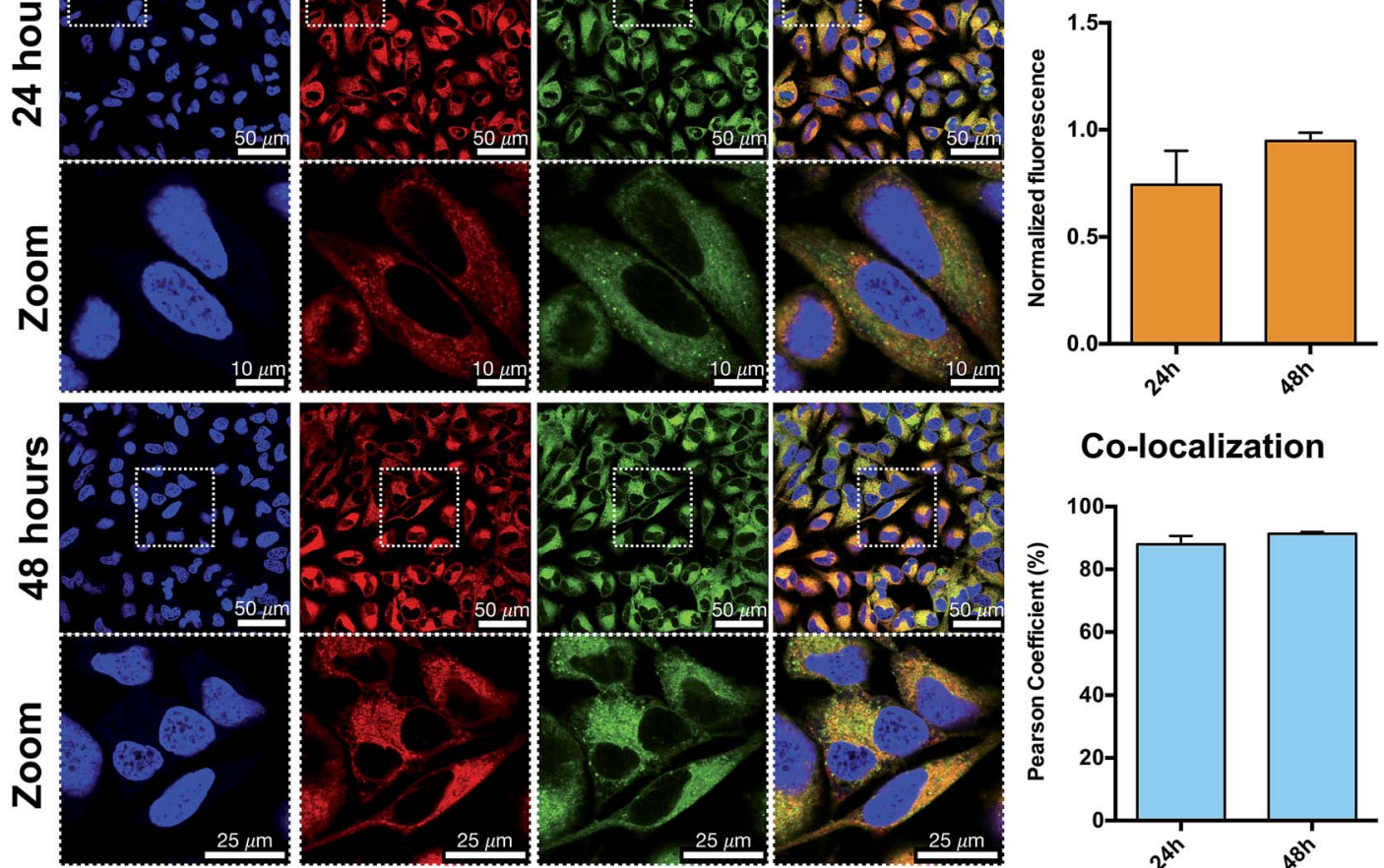

\section{Co-localization}

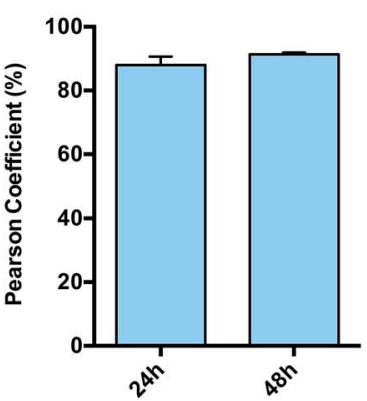

(B)
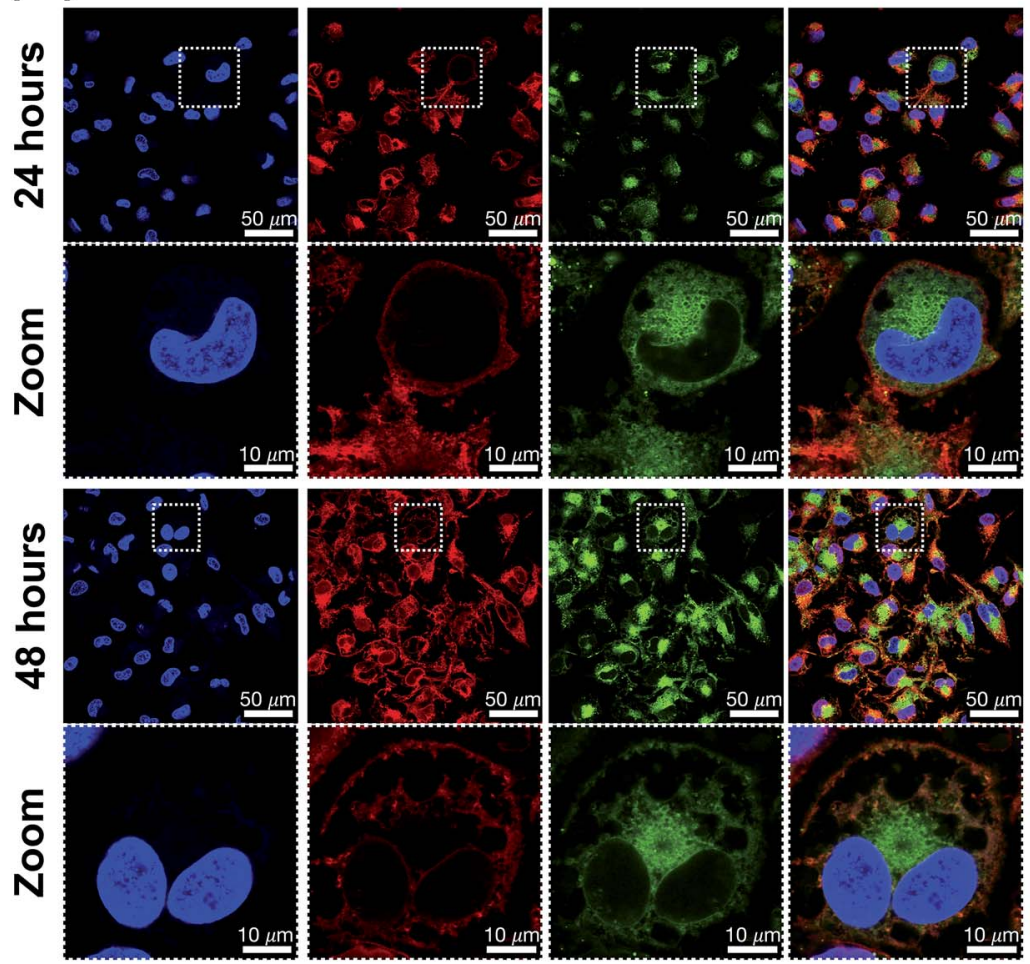

Uptake quantification
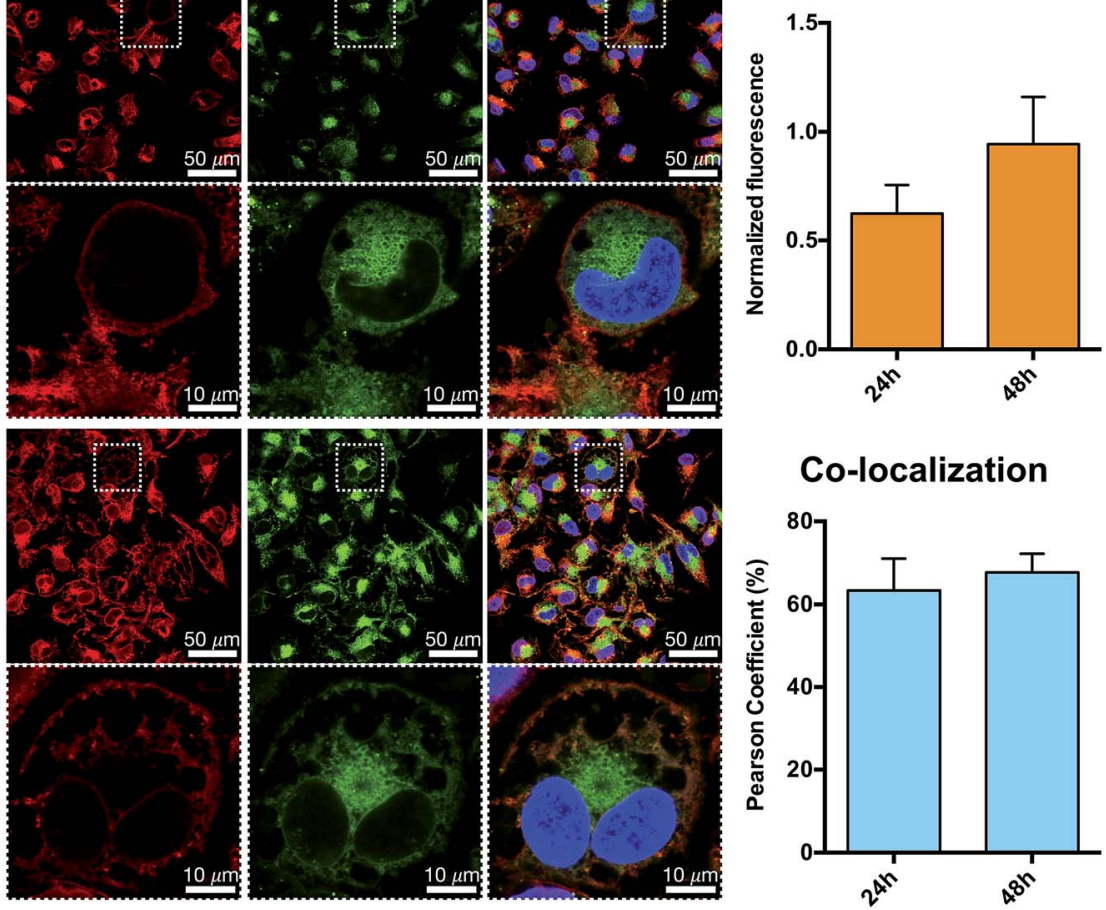

Fig. 3 Uptake study of CANVs in HeLa cells (A) and $M \Phi(B)$ after 24 and 48 hours of incubation. The dashed squares are higher magnification images of the selected area. Uptake quantification and co-localization studies are reported on the right-hand side.

potential mechanisms of toxicity and tried to understand whether nanovesicles induce inflammation in $\mathrm{M} \Phi$. To do this, we used THP1-NF- $\mathrm{BB}$ reporter cells, which are extremely powerful to monitor and quantify the level of translocation of the transcription factor NF- $\mathrm{KB}$ from the cytosol to the nucleus. This translocation occurs when $\mathrm{M} \Phi$ have to start an 

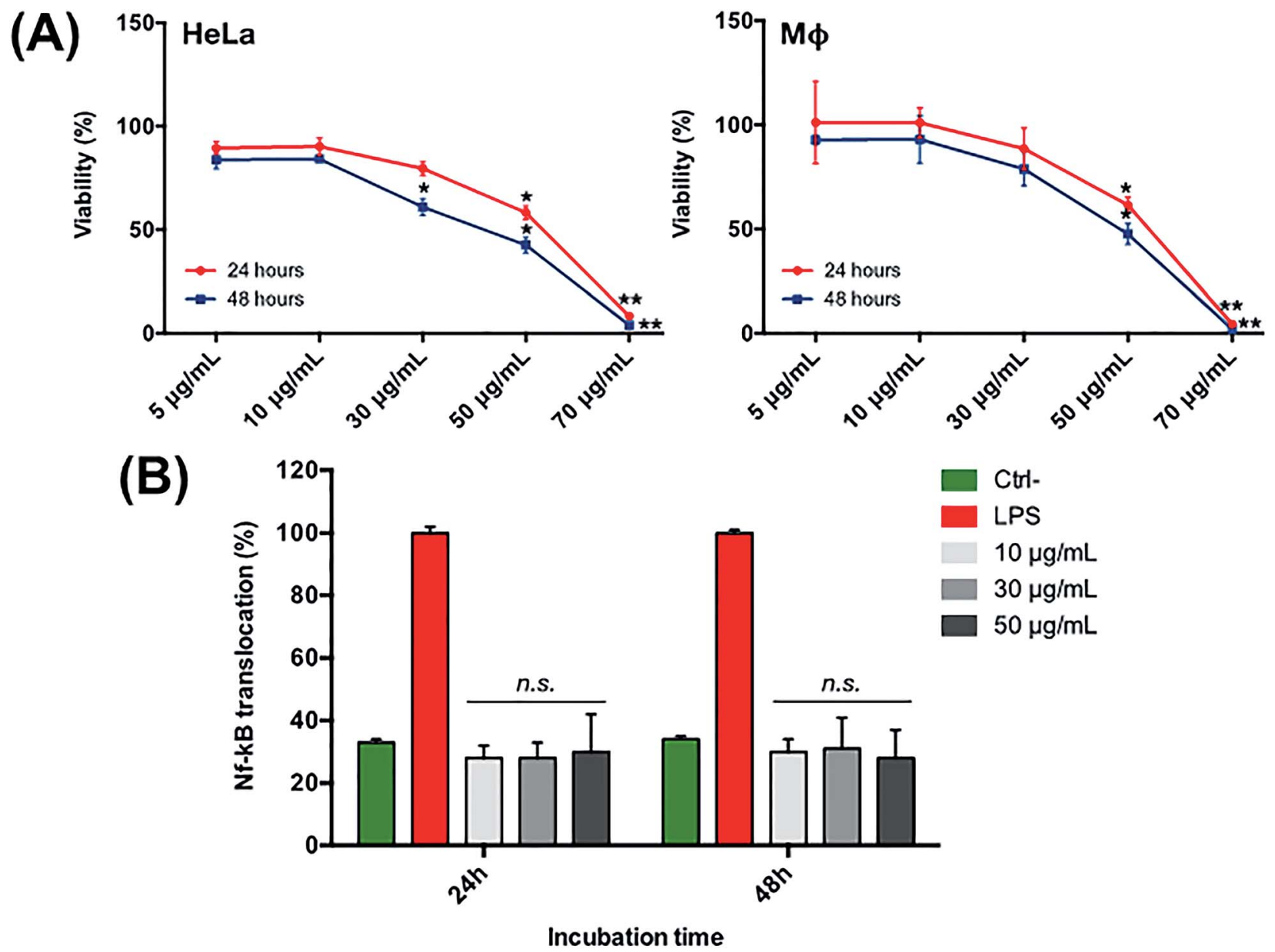

Fig. 4 (A) Metabolic assay (MTT) to test the viability of HeLa cells (left) and $M \Phi$ (right) upon incubation with 5, 10, 30, 50, and 70 $\mu \mathrm{g} \mathrm{mL} \mathrm{mLANV}^{-1} \mathrm{CAN}$ after 24 (red) and 48 (blue) hours of incubation. (B) Inflammation measurement: quantification of the SEAP activity in M $\Phi$, which indicates the levels of NF- $\kappa B$ translocation from the cytosol to the nucleus.

inflammation process upon external stimuli (like the presence of bacterial lipopolysaccharides - LPS). The nuclear translocation of NF- $\mathrm{KB}$ induces then the production of cytokines, which are the key players in inflammation. The THP1-NF- $\mathrm{BB}$ reporter cells used in this work carry a stable integration of an NF-KB-inducible SEAP reporter construct. Hence, we are able to quantify NF-KB translocation/activation through the quantification of the SEAP activity. We thus incubated M $\Phi$ with LPS as a positive control, as it induces a full NF- $\mathrm{KB}$ translocation from the cytosol to the nucleus, and we normalized the other conditions according to this treatment (Fig. 4B). We did not detect any significant increase in the SEAP activity under all the conditions tested $\left(10,30\right.$, and $\left.50 \mu \mathrm{g} \mathrm{mL}{ }^{-1} \mathrm{CANVs}\right)$, compared to control untreated cells. This indicates that CANVs do not promote inflammation, which is absolutely crucial for any biomedical application of these nanosystems.

\section{Conclusions}

The current need for exploring and deciphering basic biological phenomena requires the development of new and effective bioimaging nanotools. While doing this, nature-inspired products should be used for the design of nano-vehicles as they represent a safe, inexpensive, renewable and theoretically unlimited resource. In this context, we exploited a natural byproduct of the cashew industry, cardanol, and combined it with cholesterol for the development of cardanol-nanovesicles by a green chemistry approach. We encapsulated the nano-vesicles with a fluorescent dye (rhodamine) and demonstrated that human HeLa and THP1 (macrophages) cells efficiently uptake them. The nanovesicles have also been demonstrated to uniformly stain the cell plasma membrane, a process having high impact in imaging-based applications. Finally, we demonstrated also that CANVs are biocompatible in a specific concentration range, and do not induce any inflammation process in macrophages.

\section{Conflicts of interest}

The authors declare that there are no conflicts of interest in this work. 


\section{Acknowledgements}

Ermelinda Bloise thanks Apulian Region Programs for financial support (Intervento cofinanziato dal Fondo di Sviluppo e Coesione 2007-2013 - APQ Ricerca Regione Puglia "Programma regionale a sostegno della specializzazione intelligente e della sostenibilità sociale ed ambientale - Future In Research" Grant XYA7HY5). Loris Rizzello acknowledges the Marie Skłodowska-Curie Actions for funding his fellowship and research activities.

\section{References}

1 P. Falagan-Lotsch, E. M. Grzincicand and C. J. Murphy, Bioconjugate Chem., 2017, 28, 135.

2 W. Fan, B. Yung, P. Huang and X. Chen, Chem. Rev., 2017, 117, 13566.

3 S. Aftab, A. Shah, A. Nadhman, S. Kurbanoglu, S. A. Ozkan, D. D. Dionysiou, S. S. Shukla and T. M. Aminabhavi, Int. J. Pharm., 2018, 540, 132.

4 A. Jain, R. Kumari, A. Tiwari, A. Verma, A. Tripathi, A. Shivastava and S. K. Jain, Curr. Drug Targets, 2018, 19(13), 1498-1518.

5 L. Rizzello, R. Cingolani and P. P. Pompa, Nanomedicine, 2013, 8, 807.

6 D. Bobo, K. J. Robinson, J. Islam, K. J. Thurecht and S. R. Corrie, Pharm. Res., 2016, 33, 2373.

7 Y. Liu and N. Feng, Adv. Colloid Interface Sci., 2015, 221, 60. 8 R. Watkins, L. Wu, C. Zhang, R. M. Davis and B. Xu, Int. J. Nanomed., 2015, 10, 6055.

9 P. Loyer and S. Cammas-Marion, J. Drug Targeting, 2014, 22, 556.

10 L. Guan, L. Rizzello and G. Battaglia, Nanomedicine, 2015, 10, 2757.

11 A. Gandini and T. M. Lacerda, Prog. Polym. Sci., 2015, 48, 1.

12 P. S. Pramod, R. Shah and M. Jayakannan, Nanoscale, 2015, 7, 6636.

13 W. E. Rudzinski, A. Palacios, A. Ahmed, M. A. Lane and T. M. Aminabhavi, Carbohydr. Polym., 2016, 147, 323.

14 A. Abruzzo, G. Zuccheri, F. Belluti, S. Provenzano, L. Verardi, F. Bigucci, T. Cerchiara, B. Luppi and N. Calonghi, Colloids Surf., B, 2016, 145, 362.
15 I. Lacatusu, N. Badea, G. Badea, O. Oprea, M. A. Mihaila, D. A. Kaya, R. Stan and A. Meghea, Mater. Sci. Eng., C, 2015, 56, 88.

16 R. Amorati, O. A. Attanasi, G. Favi, S. Menichetti, G. F. Pedulli and C. Viglianisi, Org. Biomol. Chem., 2011, 9, 1352.

17 D. Teerasripreecha, P. Phuwapraisirisan, S. Puthong, K. Kimura, M. Okuyama, H. Mori, A. Kimura and C. Chanchao, BMC Complementary Altern. Med., 2012, 12, 27. 18 L. S. Parasa, S. R. Tumati, C. Kumar, S. P. Chigurupati and G. S. Rao, Int. J. Pharm. Pharm. Sci., 2011, 3, 436.

19 D. Lomonaco, G. M. P. Santiago, Y. S. Ferreira, Â. M. C. Arriaga, S. E. Mazzetto, G. Mele and G. Vasapollo, Green Chem., 2009, 11, 31.

20 F. B. Hamad and E. B. Mubofu, Int. J. Mol. Sci., 2015, 16, 8569.

21 A. Al-Hazzani, V. Periyasamy, P. Subash-Babu and A. A. Alshatwi, Med. Chem. Res., 2012, 21, 1384.

22 E. Bloise, L. Carbone, G. Colafemmina, L. D'Accolti, S. E. Mazzetto, G. Vasapollo and G. Mele, Molecules, 2012, 17, 12252.

23 E. Bloise, M. Becerra-Herrera, G. Mele, A. Sayago, L. Carbone, L. D'Accolti, S. E. Mazzetto and G. Vasapollo, ACS Sustainable Chem. Eng., 2014, 2, 1299.

24 M. S. Behalo, E. Bloise, L. Carbone, R. Del Sole, D. Lomonaco, S. E. Mazzetto, G. Mele and L. Mergola, J. Exp. Nanosci., 2016, 11, 1274.

25 M. P. Di Bello, E. Bloise, S. E. Mazzetto and G. Mele, ACS Sustainable Chem. Eng., 2017, 5, 8870.

26 O. S. Wolfbeis, Chem. Soc. Rev., 2015, 44, 4743.

27 B. Miksa, Med. Chem., 2016, 6, 611.

28 J. M. Rios de la Rosa, A. Tirella, A. Gennari, I. J. Stratford and N. Tirelli, Adv. Healthcare Mater., 2017, 6, 1.

29 M. B. Elsner, H. M. Herold, S. Müller-Herrmann, H. Bargelaand and T. Scheibel, Biomater. Sci., 2015, 3, 543.

30 S. K. Sriraman, G. Salzano, C. Sarisozen and V. Torchilin, Eur. J. Pharm. Biopharm., 2016, 105, 40.

31 H. I. Oh, T. S. Shin and E. J. Chang, Asian-Australas. J. Anim. Sci., 2001, 14, 1465.

32 M. Daigneault, J. A. Preston, H. M. Marriott, M. K. B. Whyte and D. H. Dockrell, PLoS One, 2010, 5, 1.

33 E. K. Park, H. S. Jung, H. I. Yang, M. C. Yoo, C. Kim and K. S. Kim, Inflammation Res., 2007, 56, 45. 